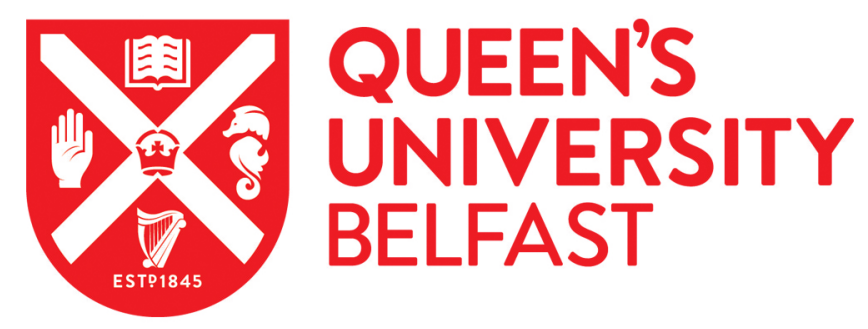

\title{
Severe or Lenient Contracting with Friends: The Shadow of the Past on Contractual Governance
}

Wang, L., Li, X., \& Zhang, M. (2019). Severe or Lenient Contracting with Friends: The Shadow of the Past on Contractual Governance. Baltic Journal of Management, 14(3), 370-388. https://doi.org/10.1108/BJM-04-20180146

Published in:

Baltic Journal of Management

Document Version:

Peer reviewed version

Queen's University Belfast - Research Portal:

Link to publication record in Queen's University Belfast Research Portal

Publisher rights

(c) 2019 Emerald Publishing Limited. This work is made available online in accordance with the publisher's policies. Please refer to any applicable terms of use of the publisher.

\section{General rights}

Copyright for the publications made accessible via the Queen's University Belfast Research Portal is retained by the author(s) and / or other copyright owners and it is a condition of accessing these publications that users recognise and abide by the legal requirements associated with these rights.

Take down policy

The Research Portal is Queen's institutional repository that provides access to Queen's research output. Every effort has been made to ensure that content in the Research Portal does not infringe any person's rights, or applicable UK laws. If you discover content in the Research Portal that you believe breaches copyright or violates any law, please contact openaccess@qub.ac.uk. 


\title{
Severe or Lenient Contracting with Friends: The Shadow of the Past on \\ Contractual Governance
}

\begin{abstract}
Purpose - The purpose of this paper is to empirically investigate the effects of cooperation history on contractual governance and the moderating effects of dependence asymmetry on those relationships from the perspective of a weaker firm in emergent economies. Drawing from resource dependence theory and contingency theory, this paper develops a conceptual model to investigate the impact of cooperation history on contractual governance.
\end{abstract}

Design/methodology/approach - The authors use data from188 buyer-supplier relationships in China.

Findings - The authors find that cooperation history is positively associated with contractual governance when dependence asymmetry is high but negatively associated with contractual governance when dependence asymmetry is low. Furthermore, the negative moderating effect of dependence asymmetry on the relationship between cooperation history and contractual complexity is stronger than the relationship between cooperation history and contract enforcement.

Originality/value - This study contributes to a better understanding of how cooperation history affects contractual governance with respect to the various levels of dependence on partners by incorporating a contingency view. This study also advances the literature on interfirm governance by distinguishing contractual governance into contractual 
complexity and contract enforcement.

\section{Key words}

Cooperation history; contractual complexity; contract enforcement; dependence asymmetry 


\section{Introduction}

Research on supply chain and strategic management indicates that successful interfirm relationships contribute critically to a firm's competitive advantage (Poppo et al., 2015). Firms can benefit from collaborating with known firms, as firms can enjoy the benefits of codeveloped routines and have greater capacity for adaptation and flexibility (Holloway and Parmigiani, 2016). Contractual governance is still undeniably essential in cooperation with old friends. The contract refers to a formal agreement that specify the roles and responsibilities of each party, monitoring methods and penalties for contract violation, and the distribution of outcomes (Abdi and Aulakh, 2012; Huber et al., 2013). Correspondingly, contractual governance refers to managing interfirm relationships though a legally binding agreement (Cao and Lumineau, 2015).Formal contracts play an important role in interparty relationship management by stipulating each party's responsibilities and rights, guiding interfirm behaviors and specifying procedures and policies to adapt to changing environments (Schepker et al., 2014; Ariño et al., 2014). However, a detailed contract may signify distrust, which will lead to psychological reactance between old friends (Zhou and Xu, 2012). In China, the strict enforcement of contract provisions may also be regarded as an insult to the buyersupplier relationship (Wei et al., 2018). In consideration of these competing influences of contractual governance on interfirm relationships, we are less certain about the relationship between cooperation history and contractual governance.

First, the theoretical predictions regarding the relationship between cooperation history and contractual governance remain conflicted (Reuer and Arino, 2007; Dekker and Alexandra, 2010; Corts and Singh, 2004). Studies rooted in social exchange theory 
have indicated that shared history can enable firms to use less complex contracts through accumulated trust and norms (Reuer and Arino, 2007). In contrast, building on the perspective of "learning to contract", some researchers have suggested that a history of prior interactions may facilitate the development of contract governance by integrating more detailed or specific knowledge into contracts (Dekker and Alexandra, 2010; Vanneste and Puranam, 2010).

Second, few studies have paid attention to the role of exchange characteristics when examining the relationship between cooperation history and contractual governance (Zhou and Poppo 2010; Bai et al. 2016). Extant research recognizes that long-term interfirm relationships allow one partner to internalize the other's skills (Holloway and Parmigiani, 2016; Arino, Reuer, Mayer and Jane, 2014). However, under the condition of dependence asymmetry, the weaker firm is less able to acquire direct control over valued resources (Casciaro and Piskorski, 2005). Dependence asymmetry refers to the difference between the focal firm's dependence and the partner's dependence on the focal firm, which reflects the extent to which interfirm relative dependencies are balanced or imbalanced (Feldman and Orlikowski, 2011). With the increase of dependence asymmetry, retaliation from the weaker firm becomes less likely and less damaging(Kumar et al., 1995). The stronger firm becomes more likely to behave opportunistically because of the decrease of fear of retaliatory acts (Shen, Wang and Teng, 2017). Therefore, the threat of opportunism may curtail the positive effect of cooperation history on trust, and the weaker firm is likely to be more motivated to learn to contract. In this case, dependence asymmetry may complicate the 
relationship between cooperation history and contractual governance.

Third, few studies consider contract enforcement or distinguish the effects of cooperation history on contractual complexity and contract enforcement in interfirm relationships(Zhou and Poppo 2010; Bai et al. 2016). As Zhou and Poppo (2010) noted, transaction cost economics is grounded in an institutional environment in which the enforcement of contract laws is effective. A key feature of emerging countries is their undeveloped legal frameworks (Peng, 2003). Emerging economies are "low-income, rapid-growth countries using economic liberalization as their primary engine of growth" (Zhou, Li and Sheng, 2014). China, for instance, lacks a stable and ineffective institutional environment for contract enforcement in some parts of its vast regions (Zhou and $\mathrm{Xu}, 2012$ ). Therefore, the enforcement of contracts may be subject to strong government or personal accommodation (Zhou and Poppo, 2010). It is possible that the influence of shared history on contractual complexity and enforcement is different because the enforcement of contracts may be limited in emerging countries.

Therefore, this paper aims to further investigate the relationship between cooperation history and contractual governance from the perspective of a weaker firm. Based on resource dependence theory and the contingency perspective, we focuses on the moderating effect of the dependence asymmetry and divide contractual governance into complexity and enforcement to fulfill these gaps. To test our conceptual model, we gather a sample consisting of 188 buyer-supplier relationships from six major provinces/cities in China. This study contributes to the literature in several ways. First, this study reveals in theory why conflicting views exist on the relationship between 
cooperation history and contractual governance by considering the contingent role of dependence asymmetry. Second, the study explicitly indicates that dependence asymmetry has significantly stronger moderating effects on the relationship between cooperation history and contractual complexity than on the relationship between cooperation history and contract enforcement.

Insert Figure 1 about here

\section{Theoretical background}

\subsection{Shadow of the past on contractual governance}

Contracts play a critical role in safeguarding investments and coordinating relationships (Schepker et al., 2014). However, it should be noted that no matter how detailed contracts are, their effectiveness depends mainly on contract enforcement (Zhou and $\mathrm{Wu}, 2010$ ). Contract enforcement refers to the severity of the degree to which a firm manages the interfirm relationship using contracts (Holloway and Parmigiani, 2016). In reality, contracts can be enforced in a flexible way, ranging from lenient actions to tough punitive actions through a "third party" according to the actual conditions (Faems et al., 2008).

Owing to bounded rationality, contracts inevitably overlook some relevant detail (Vanneste and Puranam, 2010), and cooperation experience can help firms learn how to contract with one another more effectively (Ariño et al., 2014). Cooperation experience enables a buyer and supplier to learn how the other operates and acquire 
more partner-specific information (Dekker and Alexandra, 2010). Firms also learn how to collaborate with one another in more effective ways (Mayer and Argyres, 2004). Such a common understanding between firms may be integrated into contracts eventually (Vanneste and Puranam, 2010).

Meanwhile, trust increases with repeated interactions (Argyres and Mayer, 2007). In long-term relationships, prior transaction experiences facilitate the development of social institutions and norms that are identified by the buyer and supplier over time (Ritala et al., 2014; Poppo et al., 2008). These institutions and norms establish the foundation for the development and use of interfirm trust (Poppo et al., 2008). As cooperation progresses, trust emerges from long-term communication and joint problem solving (Edwards and Lambert, 2007). As a safeguard for deterring partner opportunism, trust is more flexible and lower cost than a contract (De Man and Roijakkers, 2009; Larsen and Lyngsie, 2016). Therefore, there will be less need for contractual governance.

\subsection{Dependence asymmetry}

According to resource dependence theory, firms that are characterized as open systems must obtain external resources through exchanges with the environment (Barringer and Harrison, 2000; Pfeffer and Salancik, 1981). The need to obtain access to these critical resources leads to firms' dependence on their partners or other units (Luo, 2002; Hamel, 1991). As Buchanan (1992) show, dependence can be divided into asymmetric and symmetric dependence. If the focal firm and its partner are similar dependent on each other, the relationship is symmetric. In the contrast, if one partner is 
more dependent on the other one, the relationship is asymmetric. Dependence asymmetry arises from the discrepancies in resource endowments and/or accessibility and reflects relative power between partners (Lee et al., 2014).

Dependence advantage can be construed as a source of power (Gulati \& Sytch, 2007). As dependency asymmetry increases, the relative weaker firm enjoys less autonomy (Lee et al., 2014). In addition, because the less dependent firm can inflict more serious damage in return, it is less likely for the weaker firm to severely retaliate against the partner (Antia \& Frazier, 2001). The more powerful firm has increasingly motivation to use its dominant position with self-serving purposes. In other words, the overly dependent firm is more likely to be hurt by its partner opportunistic behavior (Gulati \& Sytch, 2007).

\subsection{A contingent view of cooperation history}

According to the contingency perspective, the effects of cooperation history likely vary across different partnership characteristics and depend on the fit between them (Howard et al., 2016). Dependence asymmetry is an important interfirm characteristic that affects the interaction between the buyer and supplier (Villena and Craighead, 2016). If the supplier is more dependent on the buyer, the latter's dependence advantage can be construed as a source of its power (Gulati and Sytch, 2007). Because the buyer can inflict more severe retaliation, the supplier becomes less likely to pursue selfserving purposes, and the stronger firm becomes more likely to behave opportunistically because of its power (Shen et al., 2017). The weaker firm worries about opportunistic behavior resulting from dependence asymmetry(Shen, Wang and 
Teng, 2017), which reduces the positive effect of cooperation history on trust. Meanwhile, for the stronger firm, agreeing to a constraint absorption operation will lead to a loss of its discretion over critical resources (Casciaro and Piskorski, 2005). This phenomenon is equivalent to relinquishing the dominant position. Therefore, with an increase in dependence asymmetry, the stronger firm is likely to resist the weaker firm's attempt to learn skills (Casciaro and Piskorski, 2005). In summary, dependence asymmetry actually acts as an obstacle for the weaker firm to cultivating trust and strengthening control over the valued resource. In this case, the weaker firm needs to be safeguarded by detailed formal contracts, which reinforces the firm's motivation to learn to contract in a cooperation. Therefore, we focus on dependence asymmetry to develop a contingent view of cooperation history in buyer-supplier contexts.

\section{Hypothesis development}

\subsection{The moderating effect of dependence asymmetry}

From the contingent view, we argue that the effects of cooperation history on contractual governance will vary across the different levels of dependence asymmetry between partners. When the extent of dependence asymmetry between them is low, each party's resources are equally important for cooperation (Lee et al., 2014). Neither is inclined to act opportunistically because each mutually benefits from the specific program. Opportunistic behaviors, if they are detected, hinder the partner's willingness to devote these critical resources to the cooperation (Buchanan, 1992). In this case, cooperation history will reduce the use of complex contracts.

First, cooperation history drives expectations of continuity(Poppo et al., 2008). 
Due to the notion that the expected payoff inherent in future exchanges will outweigh the gains derived from self-interested behaviors (Poppo et al., 2008), both parties are convinced that the other side will take greater care of the relationship instead of behaving opportunistically (Cao and Lumineau, 2015; Liu et al., 2009). By creating expectations for continuity, cooperation history establishes good faith that partners will acquire resources to achieve their common goals (Edwards and Lambert, 2007). Such confidence that each firm will obey the collective norms established in prior cooperation mitigates disputes and conflicts that would otherwise be handled by contractual governance. In this case, contractual governance becomes even more supplemental. Second, in regard to restricting partner opportunism, trust serving as a relational governance mechanism has a cost advantage and is more flexible and adaptable than contractual governance (Liu et al., 2009; Zhang and Zhou, 2013). Consequently, by cultivating trust, cooperation experience can suppress the need for elaborate contractual governance and costly formal controls (Reuer and Arino, 2007).

In contrast, the negative relationship between cooperation history and contractual governance may become positive if dependence asymmetry is too strong. First, according to resource dependence theory, becoming overly dependent on a partner is risky and makes the dependent firm vulnerable because it provides incentives for the dependent partner to act opportunistically (Barringer and Harrison, 2000; Bode et al., 2011). Meanwhile, for the stronger party, the risk of noncooperation is relatively low because the weaker firm is less likely to terminate a collaboration relationship (Lee et al., 2014). Due to the low risk terminating cooperation, trust-based principles such as 
social sanctions and self-enforcement are ineffective in restraining partners' opportunistic behavior (Mahapatra et al., 2010; Yang et al., 2013). Therefore, dependence asymmetry also reduces the effect of the trust-based principle on selfinterest behaviors.

However, with the gradual deepening of the cooperation relationship, cooperative parties may identify new opportunities for the next step of cooperation (Ariño et al., 2014). When the partners want to expand the scope of their cooperation for future projects, new uncertainty arises from increased areas for cooperation (Ryall and Sampson, 2006). In this situation, despite "self-enforcement" resulting from trust constraining partners' opportunistic behaviors, relational governance may not be enough to eliminate the negative impact of dependence asymmetry on the expanded cooperation because dependence asymmetry reduces the effectiveness of social sanctions and increases the risk of the stronger partner's opportunistic behavior (Mahapatra et al., 2010; Shen, Wang and Teng, 2017; Zhang and Zhou, 2013). When effectiveness of trust is restricted by dependence asymmetry, the weaker partner must pursue other alternatives, such as complex contract or strict contract enforcement, to ensure that the stronger partner is trustworthy and will safeguard the weaker partner's interests. Therefore, complex contracts and contract enforcement are effective means of creating mutual "hostages" when the deterrent mechanism for opportunistic behaviors is deficient (Chen and Chen, 2002).

Second, the higher dependence asymmetry is, the more likely and severe the negative influence of any mistake by the stronger firm (Krishnan et al., 2006). In this 
situation, prior cooperation enables a firm to better understand its partner's procedures, operational mode and so forth by learning how to collaborate with its partner (Vanneste and Puranam, 2010). Therefore, firms can design more detailed and executable contracts in which relevant contingencies can be effectively addressed (Mayer and Argyres, 2004; Vanneste and Puranam, 2010). Then, the weaker firm can impose slightly more restrictions on the less dependent partner though strict contractual governance to reduce uncertainty. Furthermore, a more complex and executable contract also creates common knowledge that reduces the ambiguity about some contract provisions between cooperation parties. Enhanced enforceability of the contract avoids a shift in responsibility between partners and iterations that negotiate sanctions or monitoring. Therefore, we propose the following:

Hypothesis 1a: Cooperation history is positively associated with contractual complexity when dependence asymmetry between partners is high.

Hypothesis 1b: Cooperation history is negatively associated with contractual complexity when dependence asymmetry between partners is low.

Hypothesis 2a: Cooperation history is positively associated with contract enforcement when dependence asymmetry between partners is high.

Hypothesis 2b: Cooperation history is negatively associated with contract enforcement when dependence asymmetry between partners is low.

The above hypotheses suggest that over the range of dependence asymmetry, the effects of cooperation history on the two dimensions of contractual governance are nonmonotonic. On the basis of the above hypotheses, we further propose that as the 
extent of dependence asymmetry increases, the positive relationship between cooperation history and contract enforcement will increase more slowly than the relationship between cooperation history and contractual complexity. The reasons are as follows.

Resource dependence theory informs that if the focal firm is more dependent on its partner, the partner's dependence advantage can be construed as a source of partner's power (Gulati \& Sytch, 2007). Therefore, dependence asymmetry leads to a power imbalance and an advantage for the less dependent party that may limit the autonomy and constrain the behavior of the weaker party (Mahapatra et al., 2010). For a firm that is highly dependent on its partner, it is difficult to strictly use contracts to manage partnerships or severely punish the strong partner's violations of explicit contracts. The weaker firm's strong reaction to violations of the contract may infuriate its partners (Shen et al., 2017). Consequently, retaliatory actions, such as intense conflict or earlier collaboration termination, may be taken by the strong partner, which will cause more damage to the weaker firm. Therefore, as dependence on its partner increases, the weaker firm is reluctant to manage the partnership with strict contract enforcement, especially with familiar partners.

In contrast, the impact of dependence asymmetry on the relationship between cooperation history and contractual complexity is stronger than its impact on the relationship between cooperation history and contract enforcement. High dependence asymmetry will place the weaker firm in an unfavorable position (Gulati and Sytch, 2007). Overreliance on its partner increases the weaker partner's difficulties in 
inhibiting partner opportunism and behavioral uncertainty. Therefore, for the weaker firm, many requirements need to be set ex ante. First, overdependence makes the weaker firm strive for more complex contracts to impose restrictions on behavioral uncertainty and contingency. The contract provides the "reference point" that allows firms to align their actions in advance (Mayer and Argyres, 2004). As an ex ante governance mechanism, complex contracts specify the roles and responsibilities of each party, stipulate courses of action during unforeseen events, and state the major objectives to be achieved (Zhang and Zhou, 2013). Therefore, complex contracts provide the safeguard that each partner will abide by preset provisions. For example, because of the higher transparency and specificity of explicit knowledge, the firm may face more leakage risks when contributing this type of knowledge to cooperation (Becerra et al., 2008). To avoid the leakage of explicit knowledge, only if the highly dependent firm contributes enough resources will its partner share explicit knowledge and tend to adopt a more gradual approach though repeated interactions instead of a one-time large investment (Becerra et al., 2008). This tactic is likely not beneficial to effective operation because the stronger partner's caution may delay the cooperative processes. However, a well-written contract ensures explicit knowledge flows between cooperative parties and is used to accomplish collective goals by stipulating clearly how knowledge is shared and acquired (Zhang and Zhou, 2013).

Second, from the view of the weaker firm, complex contracts are also a precaution that can deter the stronger partner's opportunistic behaviors. With complex contracts, the weaker partner can leverage resources such as the courts to enforce the contract if 
the stronger partner violates its contractual obligations. The interfirm relationship literature already includes empirical evidence that is consistent with this idea. For example, Li et al. (2010) suggested that the legal and economic penalties of not fulfilling expectations deter undesirable knowledge exploitation and facilitate partners' transfer of knowledge in a preferred direction and toward a preferred level. Therefore, we propose the following:

H3: The negative moderating effect of dependence asymmetry is stronger on the relationship between cooperation history and contractual complexity than on the relationship between cooperation history and contract enforcement.

\section{Method}

\subsection{Data sources and sample}

To test the aforementioned hypotheses, this study used cross-sectional survey data from 188 buyer-supplier relationships in China. China, as an emerging economy, is characterized by underdeveloped infrastructures and a lack of well-established institutional and legal systems (Zhou and Poppo, 2010). Moreover, China has a long tradition of using relations or ties to coordinate transactions (Yeung et al., 2009) and therefore provides a rich context to test the interplay between cooperation history and contractual governance.

Because the contact information of top managers is unavailable in China, we relied on government agencies to acquire this data (Wei et al., 2017). We relied on the Bureau of Commerce to obtain a company directory for every province. Top managers 
were selected as information providers as they are familiar with inter-firm collaboration with partners. We randomly selected a sample of 800 firms located in Beijing, Guangdong, Hebei, Henan, Liaoning, and Shaanxi provinces in China. These locations were selected to represent the geographic, economic, and demographic diversity in China. For example, Guangdong is a special economic zone and the most developed area in southern China. Shaanxi is the most typical province in western China (Wang et al., 2011). Hebei, Henan and Liaoning are industrial bases in central and northeastern China (Yi et al., 2016).

Since Chinese managers generally lack adequate experience participating in such research projects, we combined the interview approach and the survey approach for data collection. We contacted the selected firms and invited them to participate in the study. If the managers agreed, we arranged for a professor and a doctoral student to visit the firm and conduct the survey. Based on these responses, we identified 317 firms that were willing to participate in this research. Specifically, in face-to-face meetings, our research team began by asking the respondents questions and recording their responses. Then, the research team merely provided the instrument and answered any requests for clarification as the respondent filled out the questionnaire. Although costly and time-consuming, the onsite survey approach enabled us to obtain high-quality data because it ensured both access to the right respondents and an accurate understanding of the survey questions ( $\mathrm{Li}$ et al., 2008).

The survey instrument was developed by the following procedures. A professor was responsible for developing the English version of the questionnaire and then 
translating it into Chinese. Then, another professor performed a back translation. Next, five in-depth interviews were conducted to verify the content and face validity of the measures. In this step, we asked senior managers to verify the relevance and completeness of the questionnaire. Based on these responses, we revised several measurement items to clarify their meaning. Then, a pilot test was conducted with 20 managers using the Chinese questionnaire.

We successfully obtained responses from 227 firms from August to December 2016. The effective response rate was $71.6 \%$. We dropped 39 cases because of excessive missing data. To assess the informants' quality, we asked the respondents to indicate how long (years) they had worked for their companies. The means were 8.04 for managers, which indicated that they were qualified respondents. Therefore, the final sample consisted of 188 buyer-supplier dyads.

Using t-tests, we compared 227 participating and 90 nonparticipating firms on firm age, size and industry. All t-statistics were insignificant. Furthermore, we split the final sample into two groups according to the questionnaire return date. The early-wave group consisted of 110 responses, while the late-wave group included 78 responses. Ttests performed on the two groups yielded no statistically significant differences for any demographic characteristics. All these analyses suggest that nonresponse bias was not a concern in our study (Armstrong and Overton 1977).

Insert Table 1 about here

\subsection{Measurements}


Based on the relevant cooperation history, the contractual governance literature and the theoretical framework described earlier, a survey instrument was designed and modified for the Chinese context. The adaptation involved making word and sentence changes to enhance understanding in the Chinese context ( $\mathrm{Li}$ and Atuahene-Gima, 2001). For example, to measure contract enforcement, we adapted items from Antia and Frazier (2001) items, such as modifying "We took strict disciplinary action against this franchisee" to "All of us abide by provisions specified in contracts without any room for negotiation". Firms often hesitate to use contracts to respond to a partner's contract violation immediately. Therefore, we deleted items such as "Our response to this violation was firm".

We asked the respondents to provide evaluations of each item on a five-point Likert scale. We measured each construct except cooperation history by averaging the items of each scale. In Appendix A, we report the scale and validity assessments.

Cooperation history. Following Poppo et al. (2008), the respondents were asked how long the focal firm had worked with the partner (in years). Because the skewness value of this variable was positive (3.23), we took its Napierian logarithm to transform this measure. Following the transformation, the skewness value was close to zero (0.25), indicating a symmetric normal distribution.

Dependence asymmetry. Dependence asymmetry involves measures of the focal firm's dependence and its perception of the partner's dependence on the focal firm (Jap and Ganesan, 2000). Following Shen et al. (2017), we measured the focal firm's and partner's dependence. Each measure contained three items. Focal firm's (partner's) 
dependence examined the degree to which the firm (partner) relied on its partner (focal firm) to accomplish goals and the potential cost of replacing the partner (the focal firm). Asymmetry dependence is the difference between the focal firm's dependence and its perception of the partner's dependence on the focal firm.

Contractual complexity. Following the work of Huo et al. (2016), we measured contractual complexity based on a six-item scale examining the degree to which the contract clearly specified and detailed the obligations and responsibilities of each party.

Contract enforcement. Following Antia and Frazier (2001), we measured contract enforcement by three items about the firm's response to the partner's violation of a contractual obligation.

Firm size, industry factors, type of partner and competitive intensity were included as control variables in our analysis. Firm size was measured by the logarithm of the number of employees (Bai et al., 2016). Firm size may affect contractual governance because larger firms tend to have more resources. We controlled for industry type with three dummy variables: mechanical, electronics and material (Bai et al., 2016). Other industries represented the baseline group. Partner type was measured by a dummy variable ( $1=$ suppliers, $0=$ all other types). Following Zhou et al. (2014), we measured competitive intensity based on a four-item scale pertaining to the degree of competition a firm faces in its industry.

\subsection{Construct validity}

We conducted exploratory factor analysis for the scale items and extracted five components: contractual complexity, contract enforcement, partner dependence, focal 
firm dependence and competitive intensity. Then, we applied a confirmatory factor analysis. The model fit the data well (chi-square $=195.324, \mathrm{p}<0.001 ; \mathrm{RMR}=0.048$, $\mathrm{GFI}=0.905, \mathrm{CFI}=0.968, \mathrm{NFI}=0.904, \mathrm{RMSE}=0.048)$. We used Cronbach's alpha and composite reliability (CR) to assess the reliability. Both Cronbach's alpha (ranging from 0.786 to 0.878 ) and $\mathrm{CR}$ (ranging from 0.887 to 0.918 ) values were above 0.70 . Thus, all the constructs demonstrated adequate reliability (Bagozzi and Yi, 1988; Nunnally, 1978).

We used the chi-square difference test and the average variance extracted (AVE) method to assess discriminant validity. First, we performed chi-square difference tests in which we compared all the constructs in pairs to determine whether the restricted model (correlation fixed at 1) was significantly worse than a freely estimated model (correlation estimated freely). All the chi-square differences were highly significant, in support of discriminant validity (Arend and Lévesque, 2010). Second, Table 1 reveals that the diagonal elements representing the square root of AVE for each construct were much higher than the off-diagonal elements, which again satisfied the criterion for discriminant validity (Zhou et al. 2014).

\subsection{Common method bias}

Because we used a single respondent to answer all of the questions, common method variance may be a potential issue (Shu et al., 2015). Therefore, this paper applied a method variance (MV) that is unrelated to at least one variable in the analysis to access common method bias (Shu et al., 2015; Lindell and Whitney, 2001). The marker was a four-item variable to assess government intervention (Shao et al., 2014; 
Sheu, 2015). The MV used was government intervention. The lowest positive correlation $(\mathrm{r}=0.014)$ between government support and other variables was used to adjust the correlations among the variables. In Table 1, we present the means, standard deviations, and correlations for all constructs. As we show in Table 1, none of the significant correlations became nonsignificant after the MV adjustment. Therefore, common method bias was unlikely to be a serious concern in this study.

Insert Table 2 about here

\subsection{Analyses and results}

To mitigate the potential threat of multicollinearity, each scale was mean centered prior to the formation of an interaction (Aiken and West, 1991). Then, we calculated variance inflation factors (VIFs). All VIFs were less than the critical threshold of 10. Therefore, multicollinearity was not significant.

A stepwise regression approach was used to test our hypotheses (Cohen et al. 2003). We entered the variables into our models in a three-step process: (1) control variables, (2) main effect variables, and (3) moderating variables. Table 2 shows the results of regression analyses of the effects of cooperation history on contractual governance. Models 1 and 4 in Table 2 were the base models that included the control variables.

Following the procedure suggested by Zhou and $\mathrm{Xu}$ (2012), in Model 3, the interaction between cooperation history and contractual governance was positive and significant $(\beta=0.307, \mathrm{p}<0.001)$, which supports the prediction of Hypothesis 1 . 
According to Model 6, the interaction between cooperation history and contractual enforcement was positive and significant $(\beta=0.271, \mathrm{p}<0.001)$, which supports the prediction of Hypothesis 2.

Furthermore, simple slope tests were used to decompose the interaction terms. We plotted the relationships in Figure 2. For Hypothesis 1, we calculated the effect of cooperation history on contractual complexity when dependence asymmetry was low and high. A low (high) level of dependence asymmetry was defined as one standard deviation below (above) the mean. Figure2a shows that cooperation history related negatively to contractual complexity for a low level of dependence asymmetry (simple slope $\beta=-0.097, p<0.1)$ but related positively to contractual complexity for a high level of dependence asymmetry $(\beta=0.271, p<0.01)$. Therefore, Hypotheses $1 \mathrm{a}$ and $1 \mathrm{~b}$ were fully supported.

Similarly, we separated the interaction term for Hypothesis 2. Figure $2 b$ shows that when dependence asymmetry is low, cooperation history related negatively to contractual enforcement (simple slope $\beta=-0.112, \mathrm{p}<0.1$ ). When dependence asymmetry was high, cooperation history related positively to contractual enforcement $(\beta=0.214, p<0.01)$. Thus, Hypotheses $2 \mathrm{a}$ and $2 \mathrm{~b}$ were fully supported.

Insert Figure 2 about here

The moderating effect of dependence asymmetry on the relationship between cooperation history and contractual complexity was 0.307 , and its moderating effect on 
the relationship between cooperation history and contract enforcement was 0.271 . There was a significant difference between these two coefficients at a level of 0.05 through the z-test (Liu et al. 2014). Therefore, the moderating effect of dependence asymmetry was stronger on contractual complexity than on contract enforcement, thus supporting Hypothesis 3.

Insert Table 3 about here

\section{Discussion}

From the above empirical results, we find that the impact of cooperation history on two aspects of contractual governance shifts from negative to positive as the level of dependence asymmetry increases. In comparison to prior research based on social exchange theory or the perspective of "learning to contract", this study, grounded in contingency theory and resource dependence theory, focuses on the moderation effect of dependence asymmetry on the relationship of cooperation history and contractual governance. To some extent, our results support the view of Zhou and Poppo (2010), who found that cooperation duration is positively related to contractual governance. Consistent with this logic, we find that prior cooperation experience facilitates contractual governance when the level of dependence asymmetry is high. However, our study extends the former study by showing that decreased dependence asymmetry causes cooperation history to inhibit contract complexity and the severity of contract enforcement. Howard et al. (2016) called for attention to contextual factors that have 
an impact on how the interfirm relationship develops. We echo these authors' appeal with regard to dependence asymmetry as an important contextual factor.

This study also finds that dependence asymmetry is a more effective way to convert cooperation history from inhibitor to inducer for contractual complexity than for contract enforcement. As our study suggests, when the level of dependence asymmetry is high, contractual governance is a necessary choice for the weaker firm to inhibit opportunistic risk and safeguard its interests. However, it is difficult for the weaker party to strongly respond to the partner's contract violation because of its disadvantaged position caused by its overdependence on its partner. The findings that the effectiveness of a complex contract may be discounted by dependence asymmetry add to previous research which confirmed that contract enforcement is shaped by a firm's ability to take a severe response (Antia and Frazier, 2001). By confirming that dependence asymmetry is more effective in inducing contractual complexity than contract enforcement, this study validates the degree of strategic interdependence is a vital factor influencing governance structure (Mahapatra et al., 2010). In line with opportunistic perspective (Shen, Wang and Teng, 2017), the result of this study prove that dependence asymmetry increases the fear of the weaker firm for the partner's opportunistic behaviors. By confirming that dependence asymmetry inhibits contract enforcement of the weaker firm, this paper also give support to the research that dependence on these resource providers is burdensome( Lee, Mun and Park, 2015).

\section{Conclusions}

\subsection{Theoretical implications}


The effect of cooperation history on contractual governance has attracted extensive attention in the buyer-supplier dyad management literature. Although the previous research demonstrates that cooperation experience has an effect on contractual governance (Vanneste and Puranam, 2010), there is an ongoing controversy regarding this relationship. This study extends this discussion by investigating the contingent effect of dependence asymmetry. The findings therefore provide three contributions.

First, a primary contribution of this study is that it integrates contingency theory and resource dependence theory to explain the relationship between cooperation history and contractual governance. According to contingency theory, the effects of cooperation history likely change across different partnership characteristics. Uncovering such contingent forces that either circumscribe or amplify the effects of cooperation history is necessary to enrich understanding and the development of a contingent view of cooperation history. Drawing on resource dependence theory, we find that cooperation history may facilitate or inhibit contractual governance, depending on organizational structure characteristics (asymmetric dependence). Such an understanding is important because the literature specifies two contrasting findings. On the one hand, cooperation experience facilitates the development of trust, ultimately reducing the need for contractual governance (Vanneste and Puranam, 2010). On the other hand, from the view of "learning to contract", cooperation experience generates learning about how to specify a contract (Mayer and Argyres 2004) and then enhances the level of contract enforcement. However, the two logics are necessarily intertwined as explanations for the relationship between cooperation history and contractual 
governance. Therefore, by integrating the contingency view and resource dependence theory, we develop a more nuanced understanding of how cooperation history affects contractual governance with respect to the various levels of dependence on partners.

Second, we shed new light on the alliance governance literature by distinguishing contractual governance into contractual complexity and contract enforcement. This distinction is important because contractual complexity and contract enforcement capture two distinct facets of contractual governance and play different governance roles in cooperation. Previous research has pointed out that the institutional environment hinders contract enforcement in emerging markets (Bai et al., 2016; Shou et al. 2016). We introduce resource dependence to the literature on contract application and identify that dependence asymmetry is a barrier to the enforcement of contracts. Drawing on resource dependence theory, our empirical results further reveal that dependence asymmetry is a significant factor that hinders contract enforcement.

Third, to some extent, our study contributes to the debate on whether the relationship between contractual governance and relational governance is complementary or substitutable. The interplay of contractual and relational governance remains equivocal (Cao and Lumineau, 2015). We focused on dependence asymmetry as one of the causes of this controversy and examined the contingent nature of the interplay between relational and contractual governance mechanisms. To some extent, our empirical findings show that relational and contractual governance mechanisms can be substitutes or complements depending on partners' interdependence level. When the level of dependence asymmetry is low, relational governance may inhibit the use of 
contractual governance. In contrast, increases in dependence asymmetry move the overly dependent party into a vulnerable position and then drive relational and contractual governance into a more complementary relationship in which relational and contractual mechanisms complement each other. Schepker et al. (2014) argued that the relationship between contractual and relational governance may depend on contextual factors. This study echoes this appeal by investigating the contingent role of dependence asymmetry between contractual and relational governance. Therefore, our findings reinforce the idea that the relationship between governance mechanisms may vary depending upon the characteristics of the partnership.

Although our findings are based on the Chinese context, they have important implications for other emerging economies. A primary characteristic of emerging countries is their incomplete legal systems; thus, relational mechanisms play an important role in these countries. For example, Michailova and Worm (2003) found that guanxi, which is known as "blat" in Russian, is similar in a number of dimensions. According to our results, due to the generation of trust, cooperation history may inhibit formal governance when dependence asymmetry is low. In Russian, relational governance based on trust is also an important way to manage interfirm relationships. Therefore, cooperation history may produce the same effects in Russia.

\subsection{Managerial implications}

This study carries some potential implications for practitioners. First, the weaker firm should actively learn how to contract with stronger partners. With an increase in dependence asymmetry, the weak firm is likely to be less able to manage dependence 
on its partner by learning skills. However, learning to contract provides the opportunity for the weaker party to design a detailed contract. In long-term cooperation, a complex contract acts as a safeguard that can deter the stronger partner's opportunism. Second, although the weaker firm seeks a more complex contract under the condition of dependence asymmetry, the detailed contract may be partially enforced. Strong contract enforcement may be harmful to long-term partnerships. Meanwhile, the less dependent firm can inflict more severe damage in return for strong contractual enforcement by the weaker firm. Therefore, managers should be cautious about contractual enforcement when they are in a weak position.

\subsection{Limitations and further research}

Our research has several limitations that open up avenues for future research. First, this study focuses primarily on dependence asymmetry to predict the relationship between cooperation history and contractual governance. We have likely ignored other factors such as institutional environment. Future research might take up this issue by integrating different theoretical perspectives to explain the effect of cooperation history on contractual governance, which will enrich our knowledge regarding this dispute.

Second, our cross-sectional sample limits the capacity to examine the casual linkage between cooperation history and contractual governance in our theoretical model. As cooperation progresses, the level of dependence asymmetry may change. For example, a firm can reduce its dependence by collaborating with its partner's competitors (Xia 2011). Longitudinal investigations could enable consideration of the dynamic of dependence asymmetry. 
Third, this study was based on the weaker firm's perspective. However, the less dependent firm enjoys favorable bargaining power against its partner in regard to contract negotiation and enforcement. Future studies might explore the relationship of cooperation history and contractual governance from the perspective of the stronger firm.

\section{Reference}

